\title{
Look at Us, We Have Anxiety: Youth, Memes, and the Power of Online Cultural Politics
}

\author{
Julian Burton
}

Julian Burton is a former teacher with a background in anthropology, media studies, and educational psychology and a recent graduate of the PhD program in childhood studies at Rutgers University-Camden. His work focuses on the intersection of young people's participation rights and online culture, particularly the ways in which online communities enable flexible and informal politically relevant expression among youth. Along with his ongoing independent research, he works as a science and technology education consultant. Email: jtd.burton@gmail.com

Childhood is often defined by social marginalizationby a denial of access to public space and voice, and the circumscription of what interests, issues, and discourses are open to young people. The internet, as a space of expression that has lowered barriers to entry and confounded attempts at social control, is one of the primary spaces in which $21^{\text {st }}$-century youth are able to resist adult efforts to regulate their agency and expression. However, it is not only the technological tools of the online world that help them to resist marginalization from public discourse in these spaces, but also its symbolic and cultural resources-shared ideas, practices, and vocabularies particular to online communities. As part of larger projects on teens' and young adults' use of online communities to engage with cultural politics, I have been investigating the use of memes-patterns of formulaic content that rise and fall in popularity in short periods of time-in social critique, ideological discourse, community building, and identity representation. This paper examines the impact of memes on cultural discourse and, indirectly, on institutional politics, exploring their potential as an empowering channel of expression as well as their ongoing use as a tool of manipulation by larger political forces. I argue that understanding the cultural power of memes and other aspects of online remix culture is vital to theorizing contemporary politics, to analyzing the experiences and identities of contemporary youth, and to preventing the worst eventualities the increasing significance of online cultural politics may enable.

Key words: youth political participation; media remix culture; cultural politics; memes
Much work in the field of childhood studies is based on an understanding of childhood as a marginalizing status and on an awareness that contemporary society reserves many basic rights and even the full recognition of personhood for individuals deemed sufficiently adult (Qvortrup, 1993). Not long after childhood studies emerged as a discrete field, Ennew (1994) raised a question that has remained fundamental to our approach: that of "how individual children surmount the obstacle of childhood" (p. 125). This "surmounting" does not imply "developing" out of childhood's supposedly intrinsic limitations, or escaping the social category of "child," but rather overcoming the socially constructed barriers that childhood confers. This question is perhaps still undertheorized in the context of a field and approach that have often focused on recognizing the cultural and social agency of young people without, as Spyrou (2011) argues, sufficiently problematizing the structurally difficult proposition of presuming that young people can speak with "authentic" voices within adultist systems of social and political power.

Understanding how young people overcome their marginalized status to participate in shaping their societies requires an examination of how they speak and act outside of those systems, working against established power structures and norms of discourse and changing the shape of the public sphere through the creation of new forms of participation (Mejias, 2006; Schultz, 2012). This paper is specifically concerned with how young people confront and circumvent marginalization 
in the realm of political participation. "Political participation" is not taken here to refer solely to engagement with electoral politics and conventional institutions of governance, or to involvement in discourse on questions and issues broadly recognized as political in nature. I instead take a broad view of politics as concerning, in Hanley's (2010) terms, social interactions, relationships, and activities that "have a common purpose [and] involve the pursuit of goals and values in conjunction with others" ("Conclusion," paras. 1-2). This encompasses patterns of "actualizing citizenship" - increasingly prioritized among youth and young adults-focused on direct engagement with cultural foundations of power rather than with representative institutions (Bennett, 2008).

Most research on the political potential of digital media focuses on the benefits conferred by technological affordances of new communications technologies - the lack of gatekeepers, easy dissemination of information, lower barriers to access, and so on (Bennett, Freelon, \& Wells, 2010). While the impact of these features of emerging media is certainly significant, I would argue that in many cases they merely provide basic conditions of possibility. It is often the culture of digital media spaces that enables them to be mobilized to significant cultural and political effect: the shared practices, vocabularies, and frames of meaning users construct through their actions and interactions.

This paper will examine the trend of cultural resistance among youth in digital spaces within a broader context of youth subcultures and political participation in recent history, examine some examples of specific ways in which elements of internet culture have been utilized by young people to combat their exclusion from political participation, and discuss broader implications of patterns like this for understanding youth and cultural politics in the digital age.

\section{Approach and methodology}

My analysis here is primarily derived from a long-term ethnographic study I conducted between 2014 and 2017 of teen and young adult users of the multimedia blogging site Tumblr. My approach to this space, conceptually and methodologically, took the form of a digital ethnography in the tradition of work by scholars like Boellstorff (2015). Rather than seeing Tumblr's digital content as a collection of cultural products or discrete communications, I frame the platform itself as a collection of public "spaces" in which cultures form and human interactions and experiences play out; this follows a longstanding academic tradition stretching back to early descriptions of "cyberspace" as "the place between the phones"-an electronic landscape generated by connected devices which is "real" and "strangely physical" to its users despite having no measurable substance (Sterling, 1992). I perceive Tumblr as a meaningful place that is produced by interaction and provides a context for interaction, a framing that foregrounds processes of collaborative meaning making and the formation of community.

My definition of a specific anthropological "fieldsite" within Tumblr was consciously amorphous and flexible. Unlike Facebook, Tumblr has no groups with explicitly defined membership, and interaction is not separated cleanly into specific semipublic channels of audience and purpose; group memberships are flexible, implied, contextual, and subjective. It is therefore impossible to clearly delineate a subcommunity of users as subjects of study. On the other hand, attempting to conduct an ethnography representative of the platform as a whole, with its hundreds of thousands of active daily users, was of course an equally unrealistic proposition. Meanwhile, attempting to confine observations to young people alone is fraught with challenges in a space that is for the most part "disembodied." However, my intent was to focus on young people's experiences, and this obviously could not be done without somehow prioritizing their inclusion over that of adults. In many ways, these difficulties mirrored the situation faced by anthropologists attempting to define coherent fieldsites in traditional, offline ethnographies-and in fact, epistemological discourse in the field has, in recent years, begun to take note of the fact that all fieldsites are deliberate, arbitrary locations, defined (consciously or unconsciously) by the researcher as a framework for study 
(Candea, 2007).

Conscious of these issues, I elected to focus on Tumblr's media fandom community - a group united by shared appreciation for books, films, television shows, and other texts. This community skews demographically young to begin with, particularly among the most active users, and I further limited the scope of my project by only following the blogs of, and directly interacting with, users who clearly stated on their personal pages that they were under the age of 21. Many of these users exhibit very high levels of engagement in this space, often spending significant amounts of time on Tumblr on a daily basis, and characterize the fandom Tumblr community as highly meaningful in their lives. I chose the fandom community as a focus because it uniquely addressed my interest in unconventional public voice and political participation. Though it is not explicitly defined as a space of political discourse, users frequently engage in both in-depth social-justice-focused critiques of popular media and complex, involved discourse on social issues unrelated to media fandom entirely, particularly those related to gender, race, and economic inequality. I conducted two years of participant observation on Tumblr for this project, following and interacting with a sample of about $200^{1}$ young people's blogs. In the second year of the project, I also conducted 27 interviews with users aged 13 to 21 . My choice to treat Tumblr itself as a cultural context led me to decide not to limit my sample by any other criteria regarding background, so I ended up with a geographically and culturally diverse sample of users, including young people from Canada, the United States, England, Scotland, Poland, India, and Brazil.

Digital ethnography presents unique ethical challenges that are not accounted for in conventional ethical approaches in anthropology or media studies. I have elsewhere written at length about these challenges and my responses to them (J. Burton, 2018). In general, the digital context and, in particular, the publicly accessible nature of Tumblr posts necessitate significant precautions in the cause of protecting participants' privacy, particularly if pseudonymous online identities are to be taken as "real" identities as deserving of protection in research as offline identities. Specific approaches to addressing this that have been used in all published work based on this project include the following:

- Tumblr usernames have been replaced with pseudonyms. I have attempted, as far as possible, to maintain a similar structure and style to users' real usernames and to retain references to specific identities and personal interests.

- Certain kinds of posts (in particular those explicitly tagged as "personal" by users) were considered "off limits" for direct reference to their specific content.

- Direct quotes from posts have been minimally edited (e.g., by changing word order or replacing words with synonyms) to prevent quoted users from being identified via web searches; this practice can be considered a form of "ethical fabrication," an approach that digital media scholars such as Markham (2012) advocate as increasingly necessary due to the decreasing reliability of data privacy.

While the majority of this paper is based on my research on Tumblr, it is, in places, further informed by observations from similar research I am currently undertaking on youth political action on Twitter, particularly the \#NeverAgain movement led by teenaged mass shooting survivors. The conceptual framework I employ here is similar, but this research was in its earliest stages as I wrote the conference paper that later became this article, and as such I am not able to give the same detail on background or research practices. 


\section{Cultural politics and digital space}

The term cultural politics refers to the way that attitudes and perspectives, as expressed through channels like media, art, and everyday interpersonal discourse, give rise to socioeconomic realities (Newell, 2014). It describes how shared concepts and perceptions that do not seem on their surface to be "about" political concerns can have far-reaching consequences for governance and power, as they may serve either to legitimate the status quo or to empower the struggle to transform society (Glick Schiller, 1997). It serves as a recognition of culture as, in Hall's terms, "the arena of consent and resistance" (1981, p. 239), a space in which systems and structures of power and hegemony are not merely expressed and represented, but built and maintained. Cultural politics can be influenced and mobilized for many purposes, and efforts to turn the new public sphere of the internet to political purposes through large-scale, informal cultural movements have had impressive impact on the institutions of conventional political power in recent years, not only increasing donations and voter turnout, but shifting conversations around key political issues (Garcia-Castañon, Rank, \& Barreto, 2011; Hall \& Sinclair, 2011). It is important to consider, however, that while research on online political discourse has tended to focus on its use as a tool for achieving clear-cut electoral and legislative goals (Kahne, Middaugh, Lee, \& Feezell, 2012), it can have far more insidious impacts. The rise and normalization of reactionary and fascist politics in various parts of the world in recent years has been, in part, the direct result of the concerted efforts of fringe groups who have been quietly waging an explicitly declared online "culture war" for years, working to normalize ideas of ethno-nationalism, authoritarian rule, Christian theocracy, and violent heteropatriarchy (Nagle, 2017).

Within the broad scope of cultural politics, cultural resistance refers specifically to marginalized groups' and individuals' use of shared meanings and symbols to contest dominant discourses and power structures by finding new ways of making sense of the world (Duncombe, 2007). It is not direct, overt opposition, but subversion through ways of thinking, speaking, and being that diverge from what is normative and accepted at the "center" of society and public discourse. Hooks (1990) describes the spaces and shared practices of marginalized groups as fruitful sites of this kind of resistance, arguing that marginality itself is "a central location for the production of a counter-hegemonic discourse that [...] offers one the possibility of a radical perspective from which to see and create, to imagine alternatives" (p. 156). It is a site and state that is excluded from a certain kind of power, but also one that nourishes the capacity to resist and to define and express oneself outside of dominant frames of meaning.

Youth subcultures are among the marginal spaces that nurture the capacity to resist in this way. They provide alternative cultural and symbolic resources for young people to construct meaning and identities outside of mainstream cultural interpretations (Brake, 1985; Warner, 2002), and thus "oppose or negotiate the dominant meaning system" (Murdock, 1974, p. 213). In the $20^{\text {th }}$ century, it became common for this kind of youth resistance to be associated with recreational and social spaces and activities, such as dance halls and arcades, and with emerging styles and forms of media, such as rock music and video games (T. Burton, 1983; Krinsky, 2008). The line between media and social space has blurred in recent years as digital media has increasingly provided "spaces" for social interaction that have been particularly popular with young people. This shift online among youth is itself characterizable as a form of resistance and rebellion, as it has occurred in large part as a direct response to increasing adult restriction of teens' ability to go out and engage with friends and peers in more conventional public spaces (boyd, 2014; Herring, 2008). At the same time, it has also enabled the mainstreaming of new patterns of engagement with media which themselves offer opportunities for cultural resistance. Patterns of pure consumption have steadily given way to "prosumption" and remix in which ordinary users actively create and edit media rather than acting as passive audiences (Ito et al., 2008), enabling forms of social participation and resistance that range from direct engagement with specific political issues, to creative reformulation of individual and group identities, to work aimed at fundamental cultural reconfiguration (Hands, 2011). 
Many of the young Tumblr users I spoke to in the course of my research on the platform described their experiences of the online world-and, more specifically, particular corners of it not frequented by parents, teachers, and adult community members-in ways that echoed hooks' discussion of marginality and possibility, and pointed to the particular importance of remix culture and creative production. They described their digital communities as spaces in which they could "be themselves" in ways for which they would be judged in their homes and schools, from relatively mundane and low-stakes aspects of identity such as hobbies and fandom interests to things like gender identities and fundamental moral and humanitarian values. They also frequently spoke of their ability to create for themselves and each other as central to forming a community with its own norms and values.

\section{Memes as symbolic resources}

Digital subcultures, like those centered around offline spaces and activities, produce and mobilize symbolic resources that their members use to define their individual identities and engage with or confront dominant cultures. Remix culture makes these symbolic resources more mutable, however. Unlike in subcultures which, for example, may invest radical cultural meaning in mass-distributed music, in remix-heavy communities, cultural products produced or edited by ordinary individuals with no particular social capital or advantages in access can quickly reach large audiences. One of the most pervasive forms these cultural products take for young people in online communities is that of internet memes-small cultural elements in the form of images, text, audio, video, or some combination thereof that are repeated and remixed on a large scale, usually becoming intensely popular and then fading into obscurity in relatively short order. It is perhaps because of their fleeting nature and minimal scale that, despite increasing understanding of the transformative importance of digital media as a whole, it still remains for media studies scholarship at large to take the broader cultural impact of memes seriously. Their potential impact on social discourse and conventional politics is increasingly recognized, however, particularly in light of the highly successful coordinated campaigns that have mobilized internet culture to affect the course of institutional politics, including in the cases of the U.S. presidential election and Brexit referendum votes in 2016 (Ross \& Rivers, 2017).

In my own research, I have found that young people in particular are consistently using the popularity and rapid spread of memes, as well as the inbuilt meanings and cultural shorthand they lend to expressions of ideas, to engage with one another on topics of societal importance outside of conventional channels of communication and frames of meaning. Their political communication through memes exemplifies a kind of engagement that has been described as "political talk" in contrast to political voice. Where claiming voice implies "speaking to power," often by necessity in spaces and times approved of by that power and through frames of meaning constructed by that power, "talk" is "horizontal" dialogue and discussion with those with whom one shares experience and status (Shor, 1980). It may be outwardly idle and without clear purpose, lacking direct links to immediate action and change, but it is a key practice of freedom because it builds empowering social ties, engenders critical thinking, and helps people form and interrogate views and opinions (Kim \& Kim, 2008). Memes' closer affinity with everyday talk than with clear, directed voice has perhaps contributed to their remaining under the radar for so long as a form of political expression, but it has also contributed to their surprising cultural power. I generally characterize engagement with cultural politics through memes as divided into three categories: construction and expression of individual identity; construction and maintenance of community and shared ideologies; and reframing of history, context, and social norms. 


\section{Identity}

The most obvious recent example of memes' capacity to be used for individual identity expression is the "tag yourself" (also often spelled "tag urself") meme, which originated on Tumblr in January of 2016 and remained popular until late 2017. Tag yourself memes present the viewer with a selection of characters or objects, either entirely made up or based on existing media texts, real-life personalities, or objects, and asks them to choose one to identify with. The first example of the meme (Figure 1) used pictures of birds and established a visual style involving colourful, deliberately poorly drawn graphics and simple, point-form text.

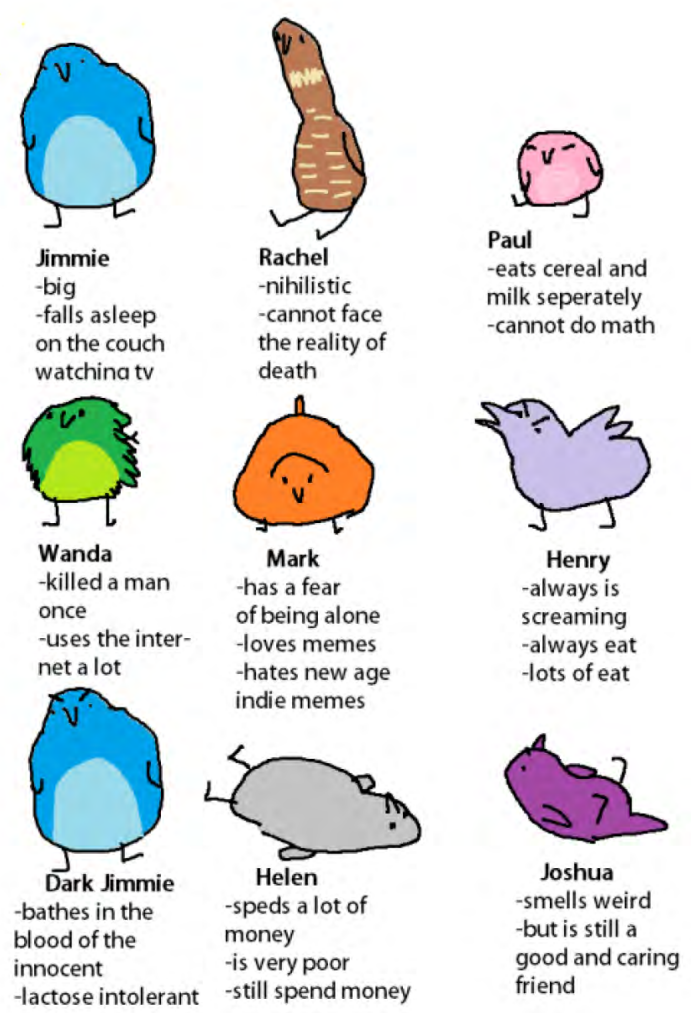

Figure 1. The first tag yourself meme.

Descriptions of characters in these memes often combine dark imagery and depressing emotional commentary with self-effacing comedy and mundane positivity. Though they tend to be very tongue-in-cheek, tag yourself memes still manage to provide a meaningful array of useful shorthand symbols for both outward self-identification and inward reflection. One Twitter user remarked in 2017, as the popularity of this meme was starting to dwindle, that "tag urself memes are really old but I hope they never die [because] deciding if I'm a bagel or eggs just helps me put life into perspective."

Other memes provide more flexible scripts for identity expression. The "prize wheel" meme (Figure 2), for instance, uses an image of a large spinning game-show-style wheel and variations of the phrase "get to know me" as shorthand for the concept of presenting "random" interests, habits, values, and past experiences that characterize a person's thoughts and expression. Users add text to the sections of the wheel to name topics and ideas that are regularly on their minds, usually in a manner that gives an impression of both surreal humour and deep personal honesty.

One 15-year-old Tumblr user I interviewed described the power of making and sharing memes like this by saying that seeing them collected on others' blogs was "like looking into the minds of people, rather than anything else." If the engagement with cultural politics is not immediately clear in examples such as these, which focus strongly on individual self-making, it is worth noting that self-representation can be as much a matter of resistance to outside expectations and perspectives as one of independent expression. As Buckingham (2008) asserts, "identity is not merely a matter of playful experimentation or 'personal growth': it is also about [...] life-or-death struggles for self-determination" (p. 1), often against significant social forces. Defining oneself through ways of communicating or in reference to ideas that are outside those preferred by mainstream society, in other words, is an act of cultural resistance because it involves pushing back against the inscription of dominant frames of meaning onto one's experiences, choices, thoughts, and beliefs. When these practices are shared among members someone: "let's talk and get to know each other!!"

me: "where should we start??"

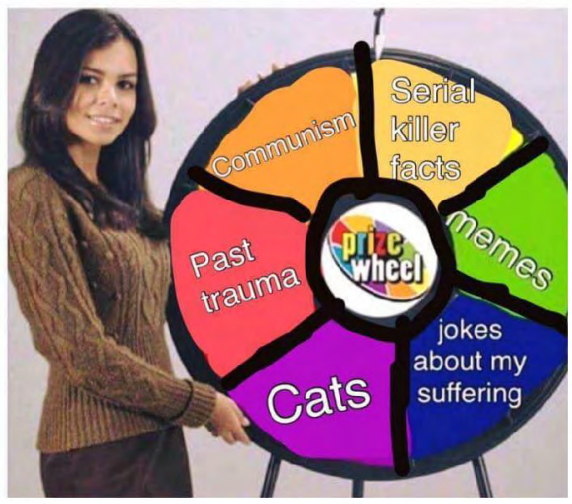

Figure 2. A "prize wheel" meme. 
of a particular subculture or marginalized group, this individual resistance to outside circumscription of identity representation becomes a form of cultural reconfiguration on a larger scale. In the case of memes representing politicized youth identities, both the message and the medium can become channels of resistance; the creator of the prize wheel meme on the previous page has used this piece of personal expression to explicitly declare themself a communist, but the way this is expressed is as disruptive as publicly identifying with an ideology derided as radical within the political mainstream.

Contemporary online youth culture, and particularly the memes and varieties of humour it tends to employ, has been described by the young people of Tumblr as "neo-Dadaist," an echo of the early-20 ${ }^{\text {th }}$-century art movement that deliberately abandoned logic and coherence as a statement on the effort it takes to make sense in a world that does not (Bruenig, 2017). The Tumblr post that popularized this term on the platform specifically describes memes filled with nonsense, obscure cultural references, and comments about suffering depression as an inescapable response to the socioeconomic conditions young people are subject to in the 2010s. Mentioning a catalogue of issues from growing income inequality and perpetual overseas war to "being called lazy and self-absorbed by the generations that gave us these problems in the first place," the post concludes, "of COURSE we make nonsense." A similar argument is applied to frank representations of depression and anxiety among online youth: as one teenaged Tumblr user I interviewed explained, in a world that sometimes seems specifically orchestrated to put young people under unmanageable pressure yet continues to treat mental health issues as shameful, the most radical response is for young people to speak openly about the issues they face and downplay the gravity of the topic. The representation of identity seen in memes like "tag yourself" and "prize wheel," while at first glance often seeming like low-stakes personal commentary, can thus be seen as a way in which young people use a shared cultural framework of cultivated senselessness and irreverence to define themselves and their experiences in relation to specific perceptions of the state of the world around them. One Tumblr user commented directly on the success of this cultivated senselessness as resistance to capitalism, pointing out that many big brands' social media marketing campaigns have failed because "they assumed the combinations of images were totally random and tried to market themselves to the new generation by deliberately creating nonsense with no deeper meaning."

\section{Community}

This leads to the second purpose memes serve in the cultural politics of online youth culture: maintaining communities and establishing shared experiences and ideologies. Sometimes the community involved is small and specific, often connected by specific interests or identities. A recent mutation of the tag yourself meme, for instance, presents users with a two-axis chart from which to choose an identity; many examples of this format (see Figure 3) place marginalized gender identities and/or sexual orientations on one axis, resulting in choices such as "distinguished gay" or "disaster lesbian." Other tag yourself memes I have encountered that are primarily relevant to specific communities include examples based on orchestral instruments, Dungeons \& Dragons classes, Star Trek characters, and $19^{\text {th }}$-century philosophers. In each case, while the meme is still primarily employed as an opportunity for individuals to

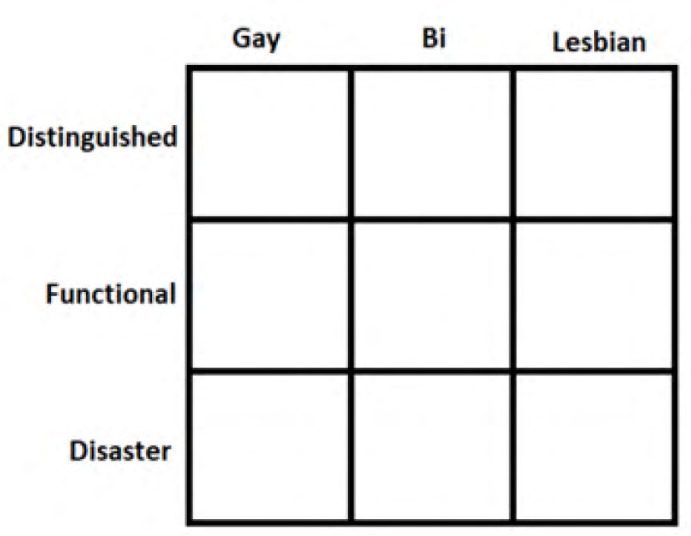

gays tag urself

Figure 3. A community-specific tag yourself meme. represent their personalities through the various captions, the source of humour in the meme as a whole is based on knowledge associated with a specific interest and membership in a specific subculture, and so sharing and 
responding to it becomes a way of signaling association with that subculture.

The meme from which this paper takes its title provides an example of how this pattern can apply to, and contribute to building solidarity within, larger social categories. In October of 2015, a user on Twitter posted a tweet reading: god: i have made Mankind

angels: you fucked up a perfectly good monkey is what you did. look at it. it's got anxiety

As this post gained popularity, users on various social media platforms began to remix its text, usually changing the words "god," "Mankind," "angels," and "monkey" to refer to the experiences (especially those that contribute to anxiety and other mental health concerns) of other groups or individuals. One Tumblr post made in early 2016 took this formula and used it to humorously remark on the increasing stress young people are put under by the education system, a common topic of conversation through which teens and young adults bond online:

University: I have made a graduate.

Student Counsellor: You've ruined a perfectly good young adult, is what you've done. Look at it. It's got anxiety.

Depending on the example in question, this community identification and recognition of shared experience may often involve identifying oneself with groups (like the LGBTQIA community) whose existence and visibility is clearly politicized, or discussing issues facing particular groups (such as stress and mental health among high school and postsecondary students) in a way that explicitly identifies a political, social, economic, or cultural problem. I have spoken with several users, for instance, whose first tentative steps out of the closet came in the form of sharing "obscure gay memes." In other cases, as with tag yourself memes that refer to media fandoms or activities like playing in an orchestra, the engagement with cultural politics may not be as obvious, yet there is still an element of the normalization and celebration of communities and ways of interacting that are misunderstood or maligned in wider society. The young people I spoke to ascribe clear importance to the existence of spaces in

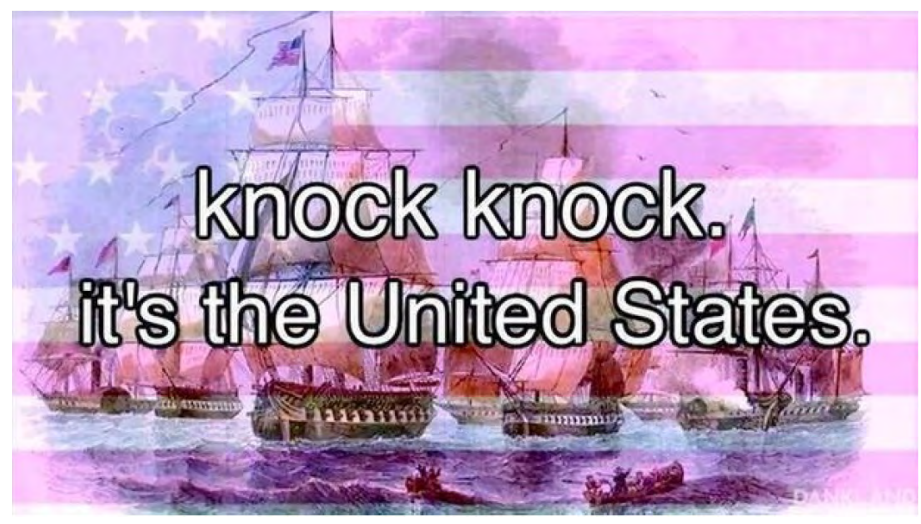

Figure 4. Knock knock. It's the United States. which they can share niche interests and create cultures that depart from framings imposed on them from without, and they also recognize the political work seemingly nonpoliticized subcultures do through this process. One young woman told me that "we [Tumblr users] are bound by our memes," describing these bits of shared expression and meaning as tools for bridging gaps of understanding and experience-and one of the reasons the communities that form around fandoms and shared interests feel, to many young people, more broadly accepting of difference and diversity than other social spaces.

\section{Cultural reframing}

The work of cultural politics done through identity- and community-focused memes tends to be implicit and secondary or even incidental to the main intent being communicated. In contrast, some uses of memes are directly and explicitly intended as cultural commentary, mobilized to express opinions on issues of social significance. This obviously can and often does take the form of expressing support for electoral candidates or partisan positions on acknowledged controversies-for instance, a tag yourself meme of the 2016 presidential candidates 
referred to Bernie Sanders as "Humanity's Last Hope" and captioned Donald Trump "do not approach under any circumstances." More interesting in the context of a discussion about cultural politics, however, is the use of memes to engage in more radical discourse: to make arguments about issues not commonly debated in the halls of government, to advance positions outside the range of those acceptable in conventional political discourse, or to express perspectives on events or issues that diverge from mainstream understandings.

In February of 2016, a YouTube user named Bill Wurtz uploaded a video called "history of japan." The video quickly went viral thanks to its combination of thoroughly researched historical analysis, irreverent tone, and excessively colourful animations, and users on several social media sites began using quotes and images from the video in unrelated conversations. Noteworthy for its lack of any one single visual or verbal script to be remixed as most memes have, "history of japan" became a flexible and relatively long-lived meme. One snippet of the video that lent itself very easily to use in various kinds of political talk was the phrase "knock knock. it's the United States." superimposed on an image of $19^{\text {th }}$-century American warships against a background of the American flag (Figure 4). Captions I have seen accompanied by this image include "when anything happens in the Middle East," "when you hear there's a war brewing in another country that you have no reason to take part in; and "when a country democratically elects a socialist government."

A similar example comes from another meme that first appeared on Reddit in 2016: the "meme economy," essentially a satirical approach to discussing the creation, consumption, and sharing of memes themselves in which they are understood through concepts relating to financial markets. Though not born specifically of online youth culture like the other examples in this paper, as the meme economy concept spread to Tumblr and Twitter for a brief period in the fall of 2017, examples became tinged with the sardonic, irreverent commentary on social norms and political institutions that are the particular hallmark of political (and particularly leftist) youth discourse online. One exchange that was shared nearly a quarter of a million times across Tumblr began when one user remarked wondering why "meme production" was in a downturn, to which another responded, "It's because school has started! [...] meme production always increases in May/June and stays consistent throughout the summer, then decreases around August"; a third user replied in affected rage, "PRIVATIZED EDUCATION AND COMPULSORY COLLEGE HAS SPIRALED US INTO A MEME RECESSION.”

These uses of these memes serve as humorous indictments of aspects of U.S. foreign policy and the contemporary education system that are in many ways uncontested in conventional political circles. Though Democrats and Republicans frequently and loudly disagree on specific campaigns undertaken by American forces overseas, a broadly interventionist foreign policy designed to strengthen American interests abroad and capitalism as a global economic system enjoy fairly consistent support among the political establishment on the left and the right. Similarly, although they may differ on how student loans should be regulated and how K-12 curriculum should be constructed, major parties in most Global North countries have generally refrained from campaigning on the idea of making any revolutionary changes in how education systems operate. In mocking interventionism and blaming schools and colleges for the "meme recession," the users posting these memes take positions outside the range of viewpoints seen as acceptable within mainstream political discourse. Their expression, though small in scale, contributes to much larger pushes to interrogate assumptions about history, international relations, and schooling, and to normalize more radical cultural discourse on these subjects.

\section{Impact and the future}

Like most technological and social changes, the rise of memes and of remix culture and online cultural politics more generally has the potential to do both good and harm. Research has found that casual engagement with social 
issues-through actions ranging from liking Facebook news posts to creating personal videos about immigrant experiences-has the cumulative effect of encouraging large-scale collective action, raising awareness of issues, increasing volunteerism and other forms of individual action, and bringing previously unheard viewpoints into the political mainstream (Jenkins, Shresthova, Gamber-Thompson, Kligler-Vilenchik, \& Zimmerman, 2016). This is particularly true among young people, for whom the internet has a primacy as a space of culturally relevant discourse it has not achieved for older generations (Kahne et al., 2012).

On the other hand, it has been established that the large-scale opening up of discourse that the internet represents comes with the risk of leading to "chaotic pluralism" - a state in which agendas and discourse are too numerous and shift too quickly for the political landscape to be fully understood-and that this political chaos may in turn give rise to populist movements (Margetts, John, Hale, \& Yasseri, 2015). Memes in particular, it has been suggested, tend to contribute to ideological chaos, both because they have difficulty accommodating nuance or complex information, favouring simplistic statements and extreme positions, and because online culture tends to favour the wide sharing of memes presenting novel or fringe positions over those advocating for anything closer to the status quo (Haddow, 2016; Mazambani, Reysen, Hempelmann, \& Carlson, 2015). This is the problem we must now grapple with, as researchers and as citizens: that the power of online cultural politics may be unequally distributed in favour of instability and, by extension, of those who would benefit from instability.

Young people are movers on all sides of this complex equation. Recent electoral successes of political candidates seen as disruptive progressives-Alexandria Ocasio-Cortez, for instance-have built on the widespread dissatisfaction with center-left neoliberals among young activists for whom online culture is the first language of politics, the socalled social justice warriors of Tumblr and Twitter who use memes to destigmatize socialism and attack American imperialism. On the other hand, despite the broad left-leaning tendencies of young people overall, and despite the fact that the "alt-right" movement as a whole is composed primarily of middle-aged people, it is young menparticularly college students-adept at navigating and influencing online culture among teens and young adults who have become the movement's most successful and visible cultural agitators (Hawley, 2017; Wendling, 2018).

There are, of course, also players in this field who are less visible, and although this paper does not intend to discuss in detail the deliberate manipulation of online cultural politics that the world is gradually becoming aware is ongoing, it would be irresponsible not to mention this as context. Recent high-profile campaigns from the Leave side of the UK's Brexit referendum to the national leadership bids of Donald Trump and Jair Bolsonaro have capitalized on rising cultures of xenophobic nationalism and anxieties about social and racial identities that would have been roundly disavowed in mainstream politics a decade ago, and which sprang to relevance thanks to concerted attempts at manipulation of cultural politics that have primarily taken place online (Douthat, 2017; Ryder, 2016). In early 2018, Tumblr - to much fanfare among its own user base but little notice in the broader media sphere-terminated 84 accounts of so-called Russian chaos agents who had been using the platform since 2015 to sow discord and undermine faith in the United States' democratic institutions. Far from the hard-right views and "fake news" propaganda pushed on Twitter and Facebook, these accounts mostly forwarded radical leftist views, often using memes and other aspects of niche internet culture as vehicles, with an undercurrent of equivocating whataboutism designed to lower progressive voter turnout by alienating young and minority voters from the Democratic party and stoking ideological arguments among leftists (Lapowsky, 2018). It is not merely foreign adversaries with chaotic agendas using online culture to manipulate cultural politics, either; alt-right leaders like the publisher of neo-Nazi blog The Daily Stormer have described "meme warfare" as "a successful attempt to formulate a new culture" friendly to their interests and antagonistic to institutions-like journalismthat would keep them in check (Haddow, 2016, para. 30). 
The nuanced deftness with which this manipulation has been and continues to be carried out is frightening, not only for its direct impact, but because it would seem to demonstrate that malicious actors with harmful agendas are much further ahead in their understanding of online cultural politics than we are as media researchers. It also shines a new light on young people's practices of resistance in these spaces. With our political institutions so far failing to catch up to the potential of online culture to reshape our social and political climate in harmful ways, the young people confronting this reactionary shift head-on with memes normalizing and advocating radical progressivism are not simply expressing themselves and bonding with one another through the sharing of entertaining nonsense-they are on the front lines of a culture war with global repercussions.

\section{Implications for research}

The cultural and political significance of memes specifically and online cultural practices more broadly have several implications for researchers. The most fundamental implication concerns how we conceptualize the internet itself as a social space and the young people who are most connected to online communities. Youth culture in general is often perceived as frivolous and the disruption of social norms it brings decried as degenerative and unworthy of serious attention; online culture, meanwhile, is frequently cast as a meaningless distraction, separated somehow from meaningful reality (Boellstorff, 2015; Sefton-Green, 1998). While these attitudes are certainly not held by most scholars whose work focuses on these areas of culture, it still often seems strange to the academy at largenever mind to the society around us - to see a research paper take online youth culture seriously as part of our social and political landscape, surrealist memes and all. It is vital, however, that we acknowledge this part of our culture, not only for its impact on our political norms, but for its importance in the lives of those who do not have equal access to other social spaces and other ways of having an impact on our cultural discourse. Fittingly, young people themselves, given the opportunity, push from the margins for a change in how we make meaning of their cultural contributions in online spaces. Many of the Tumblr users I interviewed for my research on that platform saw the divide between "online" and "real life" as artificial and needless and expressed a wish that the communities, relationships, and interactions they experienced in online spaces, as well as their own personal expression and selfrepresentation, be seen as no different from those in other contexts.

There are also implications for specific areas of research in need of attention and for the kinds of research and theoretical approaches that are needed in these areas. Memes and other products of online culture are underresearched, but more specifically, there are aspects of their power and potential in the realm of cultural politics which we urgently need to better comprehend, not only for the sake of academic curiosity, but also for that of protecting against their worst eventualities. If the political potential of memes is not evenly distributed across the political spectrum or tends toward fostering discursive chaos, either due to the nature of the medium itself or because of how it interacts with our present political institutions, our society needs data on which to base a response to this fact. The function of memes in organized campaigns of cultural politics must be understood if these campaigns are to be countered. These problems, along with the fact that media remix in general is increasingly a paradigm through which people-particularly young people-express themselves and interact on an everyday basis, point to a need for a more interdisciplinary approach to understanding online culture. This distributed, personal production of media, and the memes that are one of its most visible expressions, are deeply tied to everything from individual identity processes to global sociopolitical discourse. Developing a thorough theoretical understanding of them will require the efforts of far more than just the field of media studies.

Finally, there are practical considerations that the study of memes forces us to address, and it is likely that these are among the reasons such study has not more quickly garnered attention. It is exceptionally difficult to do any kind of in-depth research on the impact or meaning of cultural fads that appear, go global, and fade from view within 
a matter of weeks. Even if it were possible to collect meaningful data on such a phenomenon in the time before a meme falls into irrelevance, the publication process precludes any timely analysis from reaching the academic community. Perhaps we are consigned, in scholarly circles, to speak of memes in the past tense, as instances of a pattern and not as specific cultural texts or events whose impact is still unfolding and mutable, but this seems a loss of valuable perspectives. I do not have an answer to this problem to propose, but I hope, at least, to open the conversation. 


\section{References}

Bennett, W. L. (2008). Changing citizenship in the digital age. In W. L. Bennett (Ed.), Civic life online: Learning how digital media can engage youth (pp. 1-24). Cambridge, MA: The MIT Press.

Bennett, W. L., Freelon, D., \& Wells, C. (2010). Changing citizen identity and the rise of a participatory media culture. In L. Sherrod, J. Torney-Purta, \& C. Flanagan (Eds.), Handbook of research on civic engagement in youth (pp. 393-423). Hoboken, NJ: John Wiley \& Sons.

Boellstorff, T. (2015). Coming of age in second life. Princeton, NJ: Princeton University Press.

boyd, d. (2014). It's complicated: The social lives of networked teens. New Haven, CT: Yale University Press.

Brake, M. (1985). Comparative youth culture: The sociology of youth cultures and youth subcultures in America, Britain, and Canada. London, UK: Routledge.

Bruenig, E. (2017, August 11). Why is millennial humor so weird? The Washington Post. Retrieved from https://www.washingtonpost.com/ outlook/why-is-millennial-humor-so-weird/2017/08/11/64af9cae-7dd5-11e7-83c7-5bd5460f0d7e_story.html

Buckingham, D. (2008). Introducing identity. In D. Buckingham (Ed.), Youth, identity, and digital media (pp. 1-24). Cambridge, MA: MIT Press.

Burton, J. (2018). Privacy on their terms: Exploring the rights, preferences, and experiences of child participants in research in digital environments. Canadian Journal of Children's Rights, 5(1), 150-172. https://doi.org/10.22215/cjcr.v5i1

Burton, T. (1983). Video games. Games people play: Proceedings of a public conference. Edmonton: University of Alberta Department of Recreation Administration.

Candea, M. (2007). Arbitrary locations: In defence of the bounded field-site. Journal of the Royal Anthropological Institute, 13. https://doi. org/10.1111/j.1467-9655.2007.00419.x

Douthat, R. (2017, September 27). Trump's empty culture wars. The New York Times. Retrieved from https://www.nytimes.com/2017/09/27/ opinion/trumps-empty-culture-wars.html

Duncombe, S. (2007). Cultural resistance. In G. Ritzer, J. Ryan, \& B. Thorn (Eds.), The Blackwell encyclopedia of sociology (pp. $911-$ 913). Hoboken, NJ: John Wiley \& Sons. Retrieved from http://philosociology.com/UPLOADS/_PHILOSOCIOLOGY.ir_Blackwell\%20 Encyclopedia\%20of\%20Sociology_George\%20Ritzer.pdf

Ennew, J. (1994). Time for children or time for adults? In J. Qvortrup, M. Bardy, G. Sgritta, \& H. Wintersberger (Eds.), Childhood matters: Social theory, practice and politics (pp. 125-144). Aldershot, UK: Avebury Press.

Garcia-Castañon, M., Rank, A., \& Barreto, M. (2011). Plugged in or tuned out? Youth, race, and internet usage in the 2008 election. Journal of Political Marketing, 10(1-2), 115-138. Retrieved from http://www.whatkidscando.org/youth_on_the_trail_2012/pdf/ JPM_MGC_final.pdf

Glick Schiller, N. (1997). Cultural politics and the politics of culture. Identities: Global Studies in Culture and Power, 4(1), 1-7. https://doi. org/10.1080/1070289X.1997.9962580

Haddow, D. (2016, November 4). Meme warfare: How the power of mass replication has poisoned the US election. The Guardian. Retrieved from https://www.theguardian.com/us-news/2016/nov/04/political-memes-2016-election-hillary-clinton-donald-trump

Hall, S. (1981). Notes on deconstructing "the popular." In R. Samuel (Ed.), People's history and socialist theory (pp. 227-241). London, UK: Routledge.

Hall, T., \& Sinclair, B. (2011). The American internet voter. Journal of Political Marketing, 10(1-2). https://doi.org/10.1080/15377857.2 011.540194

Hands, J. (2011). @ is for activism: Dissent, resistance, and rebellion in a digital culture. London, UK: Pluto Press.

Hanley, J. (2010, December 21). What is politics? Ordinary Times. Retrieved from http://ordinary-gentlemen.com/2010/12/21/what-is- 
politics/

Hawley, G. (2017). Making sense of the alt-right. New York, NY: Columbia University Press.

Herring, S. (2008). Questioning the generational divide: Technological exoticism and adult constructions of online youth identity. In D. Buckingham (Ed.), Youth, identity, and digital media (pp. 71-92). Cambridge, MA: The MIT Press. Retrieved from https:// is.muni.cz/el/1423/jaro2013/ZUR589f/um/herring_2008_.pdf

hooks, b. (1990). Yearning: Race, gender and cultural politics. New York, NY: South End Press.

Ito, M., Horst, H., Bittanti, M., boyd, d., Herr-Stephenson, B., Lange, P., . . . \& Tripp, L. (2008). Living and learning with new media: Summary of findings from the digital youth project. Chicago, IL: The MacArthur Foundation.

Jenkins, H., Shresthova, S., Gamber-Thompson, L., Kligler-Vilenchik, N., \& Zimmerman, A. (2016). By any media necessary: The new youth activism. New York, NY: New York University Press. http://dx.doi.org/10.3983/twc.2017.1084

Kahne, J., Middaugh, E., Lee, N., \& Feezell, J. (2012). Youth online activity and exposure to diverse perspectives. New Media \& Society, 14(3). https://doi.org/10.1177/1461444811420271

Kim, J., \& Kim, E. (2008). Theorizing dialogic deliberation: Everyday political talk as communicative action and dialogue. Communication Theory, 18(1). https://doi.org/10.1111/j.1468-2885.2007.00313.x

Krinsky, C. (2008). Introduction to part I. In C. Krinsky (Ed.), Moral panics over contemporary youth culture (pp. 9-15). Farnham, UK: Ashgate.

Lapowsky, I. (2018, March 23). Tumblr finally breaks its silence on Russian propaganda. Wired. Retrieved from https://www.wired.com/ story/tumblr-russia-trolls-propaganda/

Margetts, H., John, P., Hale, S., \& Yasseri, T. (2015). Political turbulence: How social media shape collective action. Princeton, NJ: Princeton University Press.

Markham, A. (2012). Fabrication as ethical practice: Qualitative inquiry in ambiguous internet contexts. Information, Communication \& Society, 15(13), 334-353. https://doi.org/10.1080/1369118X.2011.641993

Mazambani, G., Reysen, S., Hempelmann, C., \& Carlson, M. (2015). Impact of status and meme content on spread of memes in virtual communities. Human Technology, 11(2), 148-164. http://dx.doi.org/10.17011/ht/urn.201511113638

Mejias, U. (2006, October 13). MacArthur online discussions on civic engagement: Response to question \# 1: Changing political orientations of young citizens. Retrieved from http://ccce.com.washington.edu/about/assets/Civic_Engagement-online_Discussions06.pdf

Murdock, G. (1974). Mass communications and the construction of meaning. In N. Armistead (Ed.), Reconstructing social psychology. London, UK: Penguin Books.

Nagle, A. (2017). Kill all normies: Online culture wars from 4chan and Tumblr to Trump and the alt-right. Alresford, UK: John Hunt.

Newell, S. (2014, April 1). What is meant by “cultural politics"? [blog post]. The Cultural Politics of Dirt in Africa: 1880-present. Retrieved from https://blogs.sussex.ac.uk/dirtpol/2014/04/01/what-is-meant-by-cultural-politics-by-prof-steph-newell/

Qvortrup, J. (1993). Nine theses about "childhood as a social phenomenon." In E. Centre (Ed.), Eurosocial reports: Childhood as a social phenomenon: Lessons from an international project (pp. 11-18).

Ross, A., \& Rivers, D. (2017). Digital cultures of political participation: Internet memes and the discursive delegitimization of the 2016 U.S. presidential candidates. Discourse, Context, \& Media, 16, 1-11. https://doi.org/10.1016/j.dcm.2017.01.001

Ryder, J. (2016, November 15). Western politics 2016: Brexit, Trump, and the end of the world? Prospect Journal of International Affairs at UCSD. Retrieved from https://prospectjournal.org/2016/11/15/western-politics-in-2016-brexit-trump-and-the-end-of-the-world/

Schultz, K. (2012, October 1). The fullness of silence in the classroom. Phi Delta Kappan, 94(2), 80. https://doi. org/10.11772F003172171209400223 
Sefton-Green, J. (1998). Introduction: Being young in the digital age. In J. Sefton-Green (Ed.), Digital diversions: Youth culture in the age of multimedia. London, UK: University College London Press.

Shor, I. (1980). Critical teaching and everyday life. Boston, MA: South End Press.

Spyrou, S. (2011). The limits of children's voices: From authenticity to critical, reflexive representation. Childhood, 11. https://doi. org/10.1177/0907568210387834

Sterling, B. (1992). The hacker crackdown: Law and disorder on the electronic frontier. New York, NY: Bantam Books.

Warner, M. (2002). Publics and counterpublics. New York, NY: Zone Books.

Wendling, M. (2018). Alt-right: From 4chan to the White House. London, UK: Pluto Press.

\section{(Endnotes)}

This number is approximate because of the fluid nature of the community. I continually updated my list of followed blogs as new users joined Tumblr, established users left the platform, and active users with shifting interests moved in and out of my communities of interest. 